\title{
Indicações a seguir no tratamento moral da loucura*
}

François Leuret

Compreendem-se, sob a denominação de loucura ou alienação mental, vários estados bastante diferentes uns dos outros, cuja distinção é importante para tratá-los convenientemente. Aquele que confundisse entre si esses estados doentios e lhes pretendesse aplicar uma medicação uniforme provaria somente não tê-los estudado.

Nestes últimos tempos, vem-se, portanto, tentando, caracterizar a loucura ou alienação mental como uma única e mesma doença. Infelizmente não seria uma novidade se tivéssemos nos reportado bem além dos tempos hipocráticos. Mas os que têm tido tal pretensão sabiam disso, e eu estou certo disto, mesmo que não o tenham dito. Na prática, eles se abstêm bem de aplicar sua doutrina. Para mim, longe de admitir que se tem feito um grande número de divisões, percebo que se está, ao contrário, muito mais restrito; que é preciso dividir ainda, e parar somente quando se tiverem determinado os gêneros da loucura que possam servir de guia no seu tratamento.

* Leuret, F. Indications à suivre dans le tratement moral de la folie, 1845. 
Dizer, por exemplo, que para combater as monomanias se empregam, com sucesso, os purgativos, as emissões sangüíneas, as vesicatórias, os banhos, as duchas, o isolamento, o trabalho, as viagens etc., é dizer uma verdade, mas uma verdade infértil, porque não se restringe o tratamento à patologia. Esquirol fez bem em sair das generalidades, nas quais permanecíamos até este momento. A lembrança dos serviços que, nesse aspecto e sob muitos outros ele contribuiu para a ciência, deve ser preciosamente conservada.

A confusão de todos os gêneros de alienação em uma única doença foi, recentemente, causa da maior parte das discussões a propósito do tratamento físico e do tratamento moral da loucura. Muitos médicos têm se perguntado seriamente se um desses gêneros de tratamento mereceria ter a preferência sobre o outro. Como responder a esta questão? Uma única coisa: não se pode respondêla. Com efeito, perguntar-se-ia: nas afecções do peito, os antiflogísticos devem ser preferidos aos derivativos? Nenhum homem com conhecimento em medicina faria uma indagação semelhante, e se um leigo se arriscasse a fazê-la, poder-seia dizer-lhe: há doentes do peito que são curados pelos antiflogísticos e há outros deles que são curados pelos derivativos; encontram-se mesmo aqueles que são tratados por essas duas ordens de terapêuticas, mas com a condição de que, para empregá-las, levar-se-ia em conta a natureza, a intensidade e a duração dos sintomas. As doenças do peito, consideradas em seu conjunto, não exigem exclusivamente nem os derivativos, nem os antiflogísticos, mas cada uma dessas doenças necessita ser bem distinguida uma das outras e ser tratada pelos recursos em que o raciocínio e a experiência demonstraram-se eficazes.

Nas afecções mentais - porque o conhecimento das indicações é a única base de uma boa terapêutica - ainda há, entre os sintomas, uma diferença essencial que não existe nas doenças comuns. Aqui todos os sintomas pertencem à ordem física; lá alguns pertencem à ordem física, outros à ordem moral e, algumas vezes, os da ordem moral são os únicos dos quais se pode constatar a existência.

No tratamento das doenças, o importante, antes de tudo, é, portanto, o conhecimento das indicações a cumprir e, para obtê-lo, é preciso observar os sintomas, discernir uns dos outros, classificá-los, agrupá-los por analogias, separá-los por suas diferenças. É preciso, ainda, se se trata da loucura, distinguir os sintomas que incorrem sob os sentidos, daqueles que são acessíveis somente ao pensamento, e de ordenar os que apareceram inicialmente, quais os seguiram, a fim de, se for possível, deles estabelecer a filiação. Fora deste caminho, se está sem guia, caminha-se incerto dos recursos, eu diria mesmo do objetivo. Nessa via, muitas coisas se operam sem esforços; outras, apesar de difíceis, estão tendo êxito; outras, enfim, nos resistem, deixam-nos ao menos a convicção de que, se nós cedemos, é diante do impossível. 
Dois exemplos pelos quais eu começarei a série de observações contidas neste Memoire me servirão para demonstrar a importância que é preciso dar à pesquisa das indicações, e farão ver como doenças, na aparência análogas, deviam entretanto ser tratadas por meios diferentes. Nos dois casos, trata-se de mães de família levadas ao suicídio. As duas tiveram idéias falsas, concepções delirantes, um profundo desespero. Os sintomas físicos existiam em cada uma delas, mas o início era diferente em cada uma. Em um caso, eles tinham precedido e ocasionado a perturbação da razão; no outro, uma disposição viciosa do espírito, um grande abandono da vontade, uma condescendência habitual com os caprichos multiplicados tinham ocasionado a aberração mental, e os sintomas físicos eram somente a conseqüência dessa aberração. O tratamento de cura consistiu, na primeira doente, no emprego de meios físicos; na segunda, os meios morais foram os verdadeiros agentes da cura.

\section{Primeira observação}

\section{Lipemania; causa de natureza reumática; cura pela ajuda de meios físicos}

M me Élise tem 54 anos, viúva, mãe de duas crianças que ela ama muito; não tem alienados em sua família e sempre gozou de uma boa saúde. Sua vida foi ocupada, mas sem fadiga. $\mathrm{M}^{\mathrm{me}}$ Élise vivenciou um grande desgosto: a perda de seu marido. Teve algumas contrariedades resultantes de vários processos que lhe sucederam, mas a todas suportou sem que sua razão por isso fosse de alguma forma atingida. Por volta do fim do mês de maio de 1845, ela foi pega quase subitamente por idéias as mais sinistras. Ela se encontrava terrivelmente infeliz, sem poder explicar a si mesma a causa de sua tristeza. Ela perdeu o sono e, sem esperança de reencontrar a felicidade de outrora, fez tentativas de suicídio. Ao empreender uma viagem que lhe havia sido aconselhada com a intenção de distrair-se, viu-se a tal ponto obcecada pela idéia de consagrar-se à morte, que veio a Paris se refugiar em uma casa de saúde.

M. Récamier, M. Foville e eu vimos a doente e, após tê-la examinado bem, ouvirmos o relato de seus males, termos nos assegurado de que todas as suas funções, exceto o sono, se encontravam bem, tentamos acalmá-la, inspirar-lhe confiança no futuro. Prescrevemos-lhe os banhos, as distrações, trabalho e uma vigilância contínua. Tanto quanto sua disposição mental lhe permitiu, ela se prestou a tudo. Havíamos lhe dito que preferiríamos para ela, em lugar dos trabalhos manuais com agulha, os trabalhos de jardinagem. Ela aí se aplica, mas reclamando de tudo, com palavras sempre aflitas, algumas vezes sinistras. Era vista trabalhando com uma constância verdadeiramente meritória. 


\section{CLÁSSICOSDA \\ PSICOPATOLOGIA}

ano VIII, n. 3, set/ 2005

Suas novas ocupações, os banhos, a presença de estranhos, diante dos quais um alienado sempre se observa um pouco quando sua doença não lhe tirou o sentimento das conveniências, a confiança que ela em nós depositava, deram inicialmente a $\mathrm{M}^{\text {me }}$ Élise um pouco de calma, e mesmo um pouco de sono. A calma, no entanto, foi aparente e de curta duração. Durante algum tempo em nossas entrevistas com a doente, só obtivemos dela contínuas reedições sobre seu estado atual, sobre seu desespero, sobre a morte sinistra que a esperava e, se conseguíamos reportá-la à sua vida anterior, às causas de sua doença, ela não nos informava nada de que pudéssemos tirar proveito. O que ela havia experimentado antes era pouca coisa em comparação ao que ela sofria agora, daí a razão de não sentir vontade de falar sobre sua vida. Contudo, a força de interrogá-la, a força de exigências para obter respostas precisas, consegui saber que sua casa comumente era úmida, que ela sofrera, em diferentes ocasiões, dores nos membros; que principalmente no dia mesmo da invasão de sua doença, as dores tinham subitamente se deslocado dos membros para o alto de sua cabeça, onde ela sentia, contou, formarem-se todas as suas idéias ruins.

Uma confissão semelhante, arrancada por acaso de $\mathrm{M}^{\mathrm{me}}$ Élise, tinha sido e tornou-se para nós a mais preciosa das indicações. Um reumatismo estava lá, fixado na parte superior da cabeça, provocando-lhe uma dor permanente. Essa dor foi seguida por um violento desespero e por uma inclinação para o suicídio. Por qual sucessão de causas e de efeitos esse resultado havia sido produzido?

O vinho embriaga; a aguardente torna estúpido ou furioso; o estramônio, a beladona, o haxixe, produzem alucinações; uma irritação do cérebro ou de seus invólucros leva ao delírio. Como isso acontece? Como a introdução na economia de tal ou qual substância, como uma modificação na maneira de ser dos órgãos materiais podem perturbar o que há de mais imaterial: o sentimento e o pensamento? Alguns sábios o dizem; eu o ignoro; o que sei é que o fato existe, e, na prática, não necessito mais que isso.

Já que a causa do delírio era um reumatismo, convinha administrar os remédios próprios para combater as afecções reumáticas. Tínhamos recorrido aos banhos de vapor aromáticos e, tranqüilizados pelos sucessos obtidos em circunstâncias análogas, não tivemos receio em expor à ação do banho toda a parte craniana, mas só alcançamos, com a ajuda desse recurso, um alívio pouco expressivo. Em vista disso, tomamos a decisão de aplicar-lhe sobre o ponto doloroso um pequeno vesicatório e, quando a bolha foi formada, introduziu-se sob a epiderme cinco centésimos de um grama de extrato aquoso de ópio. À noite, a doente estava aliviada e dormiu. No dia seguinte, ela se sentia esperançosa, e seu rosto havia perdido a expressão de angústia que se tinha tornado habitual. O ópio continuou sendo-lhe administrado. Quatro vesicatórios, aplicados sucessivamente em diferentes lugares do alto da cabeça, foram necessários para o complemento 


\section{$\begin{array}{lllllll}R & E & V & \text { I } & S & T & A\end{array}$ \\ LATINOAMERICANA \\ DE PSICOPATO LOGIA \\ F U N D A M E T A L \\ ano VIII, n. 3, set/2005}

dessa medicação que, em menos de três semanas, havia feito desaparecer a dor e ao mesmo tempo os pensamentos de suicídio.

Três semanas ou mais de tratamento físico tinham, portanto, bastado, e $\mathrm{M}^{\mathrm{me}}$ Élise estava em condição de regressar à sua casa. Poucos dias após sua saída, ela reencontrou a calma e a felicidade, tão cruelmente interrompidas enquanto lhe afligiu o reumatismo cerebral.

Por que não empregamos, inicialmente, um remédio tão simples, tão bem indicado e que tão prontamente teve êxito? É que, para começar, desconhecíamos a verdadeira causa da doença. Ninguém sabia em quais circunstâncias o delírio se desenvolvera. $\mathrm{M}^{\mathrm{me}}$ Élise, ela própria, tão grande era a violência de seu problema intelectual, parecia tê-lo esquecido completamente. Falando incessantemente de suas queixas, de seus temores, perseverante em seus pedidos por um pronto alívio de seus males, considerava supérfluo nos distrair com dores, que ela sentira anteriormente, e às quais considerava insignificantes. Aí estava, entretanto, o ponto capital: um reumatismo fixado sobre os músculos, fará sofrer e constrangerá os movimentos; se ele estiver nas membranas do tubo digestivo, causará cólicas, vômitos e outros sintomas análogos dependendo de sua sede; se ele é produzido no coração, matará; se subir às partes envoltórias do cérebro, produzirá o delírio e, diante da gravidade do reumatismo, esse delírio será sem febre; ele tomará, de acordo com sua evolução, parcial ou geral, o caráter da monomania ou aquele da mania.

É preciso, portanto, em medicina mental, estabelecer distinções; é preciso então analisar, distinguir os sintomas; só assim é possível atingir um bom diagnóstico e estabelecer um modo racional de tratamento.

Descreverei agora um estado que, à primeira impressão, possuía analogia com aquele de $\mathrm{M}^{\text {me }}$ Élise, mas que, em decorrência de um exame atento, necessitou, inteiramente, de outras indicações.

\section{Segunda observação}

\section{Lipemania; tentativas de suicídio; predisposição natural às doenças nervosas; causas eficientes puramente morais; tratamento moral; cura}

No mês de julho de 1841 uma senhora foi trazida, do interior para Paris, por seu marido, que me dá sobre ela as seguintes informações. A mãe desta mulher morrera apopléctica; ela tivera um irmão atingido por epilepsia, em conseqüência de excessos venéreos e do abuso de mercúrio; uma de suas irmãs, que levava a devoção a um grau extremo, era bizarra e não parava de ocupar-se com minúcias. 


\section{CLÁSSICOSDA \\ PSICOPATOLOGIA}

ano VIII, n. 3, set/ 2005

Desde a sua juventude, a doente teve idéias singulares e caprichos que não foram devidamente corrigidos. Com 18 anos de idade, por exemplo, habituada que estava de ter sempre junto a ela uma empregada, ou uma governanta, ou alguém de sua família, não podia ficar só sem que temores quiméricos viessem assaltála. Um dia, afogara-se, em uma lagoa perto da casa onde morava, um cachorro raivoso. Profundamente impressionada com isto, ela ficou toda trêmula, como um cachorro, e recusou, durante muito tempo, passar perto da lagoa onde o animal atingido pela raiva fora jogado. Muitas outras idéias análogas vinham sucessivamente atormentá-la até a época de seu casamento. Então, e porque amava muito seu marido, ostentou uma grande tranqüilidade de espírito, a fim de não importuná-lo com o relato de temores que sabia não terem fundamentos, mas dos quais, entretanto, ela sofria o jugo. Assim, por um acidente bastante comum, essa mulher manchara de óleo suas vestes; preocupava-se com a mancha. Em seguida, com a mancha se atormentou. Depois tomou horror a óleo e, sob o pretexto de higiene, suprimiu as lâmpadas de sua casa, onde só ardia a chama da vela. A salada e todos os alimentos a óleo foram ao mesmo tempo proscritos da mesa, mas com prudência, com razões especiais e que podiam ser admitidas.

Após o temor de ficar só, em seguida àquele do cachorro e esse do azeite, sobrevinham novos temores e esses davam lugar a outros. No entanto, $\mathbf{M}^{\mathrm{me}}$ Louise (é o nome que darei a esta senhora) dirigia sua casa, supervisionava numerosos empregados, educava seus filhos (ela teve oito) e, era uma perfeita anfitriã. Ainda não estava doente, mas a ponto de tornar-se uma.

Com a idade de quarenta anos, após ter sido até aí religiosa, mas somente religiosa, ela cai sob a superstição. Passa a fomentar as idéias da religião, como fizera com as outras idéias dominantes, até o exagero, até ao absurdo. Havia comungado, e, acreditava ela, a comunhão fora feita em estado de pecado mortal, condenava-a sem remissão: a partir de então, aflição, confissões e novenas feitas inutilmente, abandono completo dos afazeres domésticos, dos cuidados com sua pessoa; em uma palavra, delírio verdadeiro, encadeamento da vontade. Até aí $\mathrm{M}^{\mathrm{me}}$ Louise tinha permanecido em parte lúcida sobre suas idéias delirantes, que só admitia com restrição e às quais cedia, é verdade, alguma parte de sua liberdade moral, mas mantendo, entretanto, bastante domínio sobre si mesma para não deixar surpreender-se, nem mesmo por seu marido. A partir do momento em que a idéia de ter profanado uma hóstia apossou-se dela, houve aí um profundo trauma das faculdades do espírito, um brutal desespero, tentativas de suicídio; em uma palavra, a loucura, por muito tempo ameaçadora, estava declarada.

Confiada aos meus cuidados, eu a examinei. Sua saúde física estava gravemente alterada, e seu delírio tinha feito progressos assustadores: estava abatida, pálida, magra, descarnada; seu hálito estava fétido, sua língua seca, seu pulso rápido e fraco; sua pele, comumente fresca, esquentava-se algumas vezes 


\section{$\begin{array}{lllllll}R & E & V & \text { I } & S & T & A\end{array}$ \\ LATINOAMERICANA \\ DE PSICOPATO LOGIA \\ F U N D A M E T A L \\ ano VIII, n. 3, set/2005}

como na febre. Várias partes de seu corpo, os braços sobretudo, apresentavam numerosas equimoses, e bastava uma ligeira pressão para neles produzir novas. O delírio era incessante, era o princípio de todas as ações, impossibilitava todas as funções submetidas ao domínio da vontade: a doente via em tudo hóstias ou profanações de hóstias. Tudo o que tinha uma forma circular, tudo o que era branco sem mesmo ter essa forma, era uma hóstia ou uma porção de hóstia. Nas batatas, nos molhos, a gordura derretida, sugerindo formas circulares, são hóstias; no pão, buracos igualmente circulares, eram ainda hóstias; na superfície das bebidas, há bolhas de gás: sempre hóstias. Não é admissível, nesse caso, beber ou comer sem temor ao sacrilégio.

No muco nasal, na saliva, na urina, nas matérias fecais, ainda as bolhas e, por conseqüência, as formas circulares: não se deve, portanto, produzir nada, pois se tornariam hóstias. De forma alguma bolsos, pois aí cairiam hóstias; nada de mudança de roupas de cama, pois, nas pregas, as hóstias poderiam ser escondidas; nada de cartas fechadas com lacre; ${ }^{1}$ nada de passeios, porque, no caminho, encontram-se pedaços de papel, de estuque, de objetos brancos que são hóstias; nunca orações na igreja, porque lá há hóstias das quais se pode apoderarse: daí a obrigação de se afastar das igrejas, de se manter bem longe delas para não escutar o som dos sinos, que lembram as igrejas, que recordam as hóstias; nada de sono, a menos que aí não se sucumba, porque, dormindo, pode-se levantar sonâmbulo e ir abrir o tabernáculo; ao despertar, pavor extremo e procura atenciosa de hóstias que poderiam se encontrar nas mãos, no leito; enfim, à noite e durante o dia, por toda parte hóstias. A vida havia se tornado, para $\mathrm{M}^{\text {me }}$ Louise e para aqueles que a rodeavam, um suplício.

Não foi de repente que ela caiu nesse excesso de delírio, mas progressivamente. $\mathrm{M}^{\mathrm{me}}$ Louise dele se escondia inicialmente, mas sucessivamente seu marido, sua família, as pessoas ao seu redor, testemunharam seus horrores e souberam-lhes o motivo. Para tranqüilizá-la, para distraí-la, foram empregados todos os meios que sugeriam a amizade mais sincera, o devotamento mais absoluto: havia-se alcançado alguma coisa, mas bem pouco.

Depois de horas, de dias de insistência e preces, se lhe fez engolir uma xícara de caldo sem gordura, um pouco de carne e de pão. Quando fatigada por esforços inauditos, ela não podia mais reter a matéria de suas dejeções, deixava-

1. A expressão pains à cacheter foi traduzida aqui por lacre, uma vez que cola de farinha de trigo, ou "cola branca", não esclareceria de que se trata, uma vez que naquela época as cartas eram fechadas com um punhado de obreia (s.f. (1689 cf. AVSerm) 1 massa de que se faz a hóstia 2 folha fina de massa de farinha de trigo, us. para cerrar cartas. ETIM fr. ant. obleie (c1200, oblee sXIV, atual oublie) "hóstia'”, der. do lat.medv. oblata (sc. hostia) "oferenda, hóstia oferecida na eucaristia”; ver -fer- e 2obr-; f.hist. 1689 obrea, 1789 obreia ). 


\section{CLÁSSICOSDA \\ PSICOPATOLOGIA}

ano VIII, n. 3, set/ 2005

a escapar, mas com pesares indizíveis. À força de súplicas, conseguia-se colocála no banho, vesti-la e despi-la, mas era sempre com uma morosidade infinita, com precauções multiplicadas, e garantia dada mil vezes de que não faria mal e de que não havia aí nenhum risco de profanação. Além de tudo isso, havia um profundo desgosto pela vida e as reiteradas tentativas de suicídio!

O que fazer se só havia o delírio, se a saúde física não tinha ficado ela mesma em um estado deplorável, nenhuma hesitação?

Era preciso romper com os velhos hábitos, afastar todas as pessoas que tão improdutivamente tentaram consolar a doente; dirigir tudo: regime, remédios, distrações, suscitar paixões, idéias medicamentosas, com o risco de contrariar e mesmo de irritar a doente. Uma cólera sobrevindo a propósito, e respondendo a uma verdadeira provocação, é cem vezes menos penosa de suportar do que o são os temores quiméricos e as idéias loucas; é, além do mais, uma paixão normal capaz de dar novamente à vontade seu domínio. Mas irritar uma mulher esgotada, alternativamente debilitada e excitada pela febre, devia eu ousá-lo? Não podia a morte, ser ela o resultado de uma impressão viva por demais? E uma vez que o perigo era grande, não era menos desprezível deixar morrer a doente do que se expor a apressar seu fim? Eu aguardei. Unindo minhas exortações àquelas do marido, disse à enferma tudo o que imaginava de mais apropriado para persuadila; usando das vantagens que junto a ela me permitia minha qualidade de médico, e de médico ao qual tinha vindo de tão longe consultar em Paris, minhas palavras não foram sem uma feliz influência.

Recomendei alimentação, banhos diários; bate-papos, os passeios a pé ou de carro, os espetáculos, acima de tudo, uma vigilância extrema e, se possível, um redobramento da amizade e da paciência.

Nos dias seguintes, eu revi a doente. Ora a encontrava um pouco melhor, ora pior: o que ganhávamos na véspera, o perdíamos no dia seguinte. Em breve, minha influência, no princípio bastante fraca, tornou-se quase nula; o marido só obtinha, quando muito, raras concessões. Para fazer a doente tomar um pouco de alimento, foi preciso atormentá-la tanto, que se tornava duvidoso para nós se nossas obsessões não lhe eram tão prejudiciais que a alimentação não podia lhe fazer bem.

O mal dominava então, mas vendo $\mathrm{M}^{\mathrm{me}}$ Louise todos os dias, aprendendo a conhecê-la bem, julgando que, apesar de sua extrema magreza, restava-lhe ainda força e tendo tido a ocasião de perceber que, diante de mim, ela não se entregava tanto às excentricidades na mesma proporção como fazia diante de seu marido, esperei.

A indicação era fácil de perceber. Não havia aí, como no caso precedente, uma doença anterior, causa da loucura; nenhuma dor trazendo como conseqüência idéias tristes e o desespero. A causa e a natureza da doença eram exclusivamente 
$\begin{array}{lllllll}R & E & V & I & S & T & A\end{array}$

LATINOAMERICANA

DE PSICOPATOLOGIA

F U N D M E N T A L

ano VIII, n. 3, set/ 2005

de ordem moral. Precisava, portanto, agir pelos meios morais, e era importante não adiar mais, porque a disposição se ia empobrecendo, e cada dia de atraso era um passo em direção ao túmulo.

Minha resolução tomada e combinada com o marido, comecei o tratamento. Uma manhã, entrei na casa da doente acompanhado por um dos meus mais destacados alunos, o doutor Perrot, e por uma criada de quarto, escolhida a mais capaz entre aquelas que eu tinha à minha disposição.

A doente pareceu espantada ao me ver, assim, escoltado, mas quando eu lhe anunciei que M. Perrot ficaria junto dela para observar a execução dos meus conselhos - até aí de modo algum seguidos - e que a criada de quarto foi contratada a seu serviço sob ordem de não deixá-la um só instante; quando acima de tudo ela entendeu que eu dispensara seu marido e que esse se dispunha a me obedecer, ela ficou surpresa, apavorada, soltou gritos, testemunha de um violento desespero.

A separação se fez não sem uma viva resistência da parte da doente. Ficando sozinha na presença de nós três e vendo-nos reunidos em um mesmo propósito, $\mathbf{M}^{\text {me }}$ Louise fez, após alguns instantes de exasperação, o que fazem quase todos os doentes, o que faria toda pessoa razoável em situação semelhante: acalma-se um pouco, e procura nos comover sobre sua posição. Tornei-me o árbitro de seu destino. Decidi mostrar-me severo: era preciso se dobrar e obter de mim o retorno do marido. Ela comeria, beberia, enfim, faria tudo o que eu desejasse. Mas na medida de suas forças e contanto que o marido estivesse com ela; sem isso, ela não escutaria nada, e se deixaria morrer.

- A sra. me promete, agora, comer e beber, o que a sra. não fazia quando seu marido estava aqui e que ele isso lhe rogava?

— Eu o farei agora. Oh! Devolva-me meu marido.

- A sra. não poderia fazer hoje mais do que a sra. não fez ontem?

- Oh! Sim, eu poderia.

- A sra. acreditaria ainda ver hóstias em seus alimentos e em suas bebidas?

- Eu farei tantos esforços sobre mim que não o acreditaria mais.

- A sra. não poderia fazer esforços suficientes para consegui-lo.

- Oh! Eu o farei, eu estou certa de fazê-lo.

- Os glóbulos de gordura que estão sobre a sopa ainda assustariam a sra.; seria isto o mesmo com as bolhas de ar que estão na superfície do leite, da água, das bebidas.

— Oh! não, eu não me assustaria mais com nada, se meu marido estiver aqui para me acalmar.

- Você se assustaria ainda, porque isso são coisas muito importantes!

— Eu sei bem que elas não são importantes.

— Como! A gordura sobre a sopa, isso não parece importante à sra.? 


\section{- Não.}

— E os pedaços de papel?

- São pedaços de papel.

- E as migalhas de pão, da farinha, o estuque, as extremidades do fio, a penugem, tudo isso se parece muito com hóstias, e o medo que a sra. tem delas me parece bem fundamentado.

— Fundamentado sobre minhas idéias, mas se eu tiver meu marido, eu delas não terei mais medo.

- E suas necessidades naturais, quando você as experimentar, você as satisfaria se seu marido estiver perto da sra.?

- Sim.

- A sra. não daria conta disto!?

— Oh! Eu daria; isso é bem fácil.

- Ah, bom! Senhora, visto que isso é fácil, faça-o por merecer, que seu marido volta. Suas promessas são belas, mas fazê-las e obtê-las não é a mesma coisa. M. Perrot está aqui, siga seus conselhos. Ele julgará seus esforços e, se você conseguir mais domínio de si, eu permitirei ao seu marido vir, mas só o permitirei sob essa condição.

Dito isso, retirei-me, deixando a M. Perrot o cuidado de conduzir a doente.

Era a hora do almoço; serviram. A doente senta-se em frente ao M. Perrot, desdobra o guardanapo com má vontade; em seguida, olhando seu prato e aí tendo encontrado um pouco de penugem, pede outro. M. Perrot aí se recusa e joga nesse mesmo prato miolo de pão. A doente irrita-se, acusa o médico de querer atormentá-la e diz formalmente que ela não comeria, e deixa a mesa.

Era preciso que ela comesse, porque estava extenuada; ela não tinha comido nada ou quase nada há vários dias. M. Perrot lhe diz: "Eu vou colocar miolo de pão no prato, nos alimentos e em seu copo, e a farei comer à força, ou então a sra. irá sentar-se, remover-se-á o prato no qual tem o miolo de pão. Em seguida, a sra. comerá e beberá voluntariamente".

Comer à força e comer miolos de pão que podem ser hóstias! É preferível mil vezes sentar-se à mesa e almoçar: foi o que fez a doente, não sem grandes hesitações, mas enfim comeu, e M. Perrot não se prestou em dizer-lhe, nem mesmo uma única vez, que ali não havia hóstia, nem em seus alimentos nem em suas bebidas.

Seria muito demorado entrar nos detalhes de tudo o que fizemos e dissemos à doente; os fatos principais serão suficientes para o leitor. O primeiro ponto era alimentá-la. Nós aí colocamos todo nosso esforço e acabamos por obter um regime regular, sem jamais condescender ao desejo que tinha sempre e que $\mathbf{M}^{\mathrm{me}}$ Louise freqüentemente testemunhava de ser tranqüilizada a respeito da presença de hóstias. Seus pedidos diretos eram sempre rejeitados, seus pedidos indiretos 
$\begin{array}{lllllll}R & E & V & I & S & T & A\end{array}$

LATINOAMERICANA

DE PSICOPATO LOGIA

F U N D A M E N TA L

ano VIII, n. 3, set/2005

não eram jamais compreendidos. Ela aí colocava, entretanto, algumas vezes, uma grande habilidade. Hábil, inteligente, espirituosa, por momentos tornava-se graciosa. No meio de uma conversa que ela sabia nos interessar, mostrava-nos um pouco de lã, um pouco de fio, um pedaço de papel, e com um olhar quase suplicante, mas sem falar, dizia: Não é uma hóstia? Nossa proposta era a de não responder e ficarmos inflexíveis, mas eu não podia garantir que ela não tenha jamais escutado de nossa boca ou lido em nossos olhos a resposta que ela desejaria. Sua pequena manobra tinha em que nos alegrar: ela indicava a habilidade. Por falar nisso, era uma astúcia que não era preciso levar muito a sério.

Os primeiros dias foram tão penosos para a doente quanto para nós. Da parte de $\mathrm{M}^{\mathrm{me}}$ Louise, resistência contra tudo; de nossa parte, a firmeza, algumas concessões e a permissão de curtas entrevistas com o marido. A esperança pelas entrevistas era a mais poderosa razão que agia sobre ela. Eu as queria curtas, porque era preciso antes estimular os sentimentos afetuosos que os satisfazer. Nosso coração é feito assim: se ele deseja, é capaz de operar prodígios; se ele tem o que quer, ele se sacia.

Eu disse que $\mathbf{M}^{\text {me }}$ Louise não se assoava, qualquer que fosse sua necessidade disto. Uma manhã em que M. Perrot conseguiu pela primeira vez obrigá-la a assoar-se, ele me partilhou sua alegria. Eu quis, para completar essa obra, que a doente pegasse ela mesma um lenço na cômoda, que dele se servisse diante de mim e que o colocasse em seu bolso; pois eu lhe havia feito ter bolsos. Ela abriu sua cômoda, mas precisamente sobre os lenços encontrava-se um pequeno pacote de pedaços de lã que ela ali tinha escondido para, quando seu marido viesse, ele dissesse a ela que os pedaços de lã não eram hóstias. Assustada com essa visão, ela se nega nitidamente a tocar nos lenços. Insisti, implorei, fiquei bravo, sem conseguir nada, e isto durou uma hora e meia. Então não tive mais nenhum recurso e, com um tom de cólera, ordenei que me trouxessem uma caixa de lacre branco, que ameacei jogar por toda parte: sobre o assoalho, sobre os móveis, sobre a doente. Atordoada com um tão rude golpe, ela pegou um lenço, tornouse sorridente para me perguntar, servindo-se dele, se ele não continha nada. Assoava-se, levantando seu lenço de maneira a não esconder a boca para que se visse bem que ela não cuspia hóstias, e colocou o lenço em seu bolso. Havia talvez um ano que não lhe acontecia coisa semelhante.

Para que ela se assoasse, como qualquer pessoa o faz, foi preciso ainda um bom tempo e sofrimento, mas, enfim, nós conseguimos obrigá-la. As outras evacuações só se regularizaram uma única vez, não exclusivamente por nossas recomendações isoladas, mas fomos obrigados a recorrer a vários estratagemas, entre os quais a idéia da caixa de lacre desempenhava também seu papel.

A preocupação com hóstias tinha corrompido todas as ações, mudado todos os hábitos. A fim de reconduzir $\mathrm{M}^{\mathrm{me}}$ Louise a seu estado normal, era preciso com- 
bater todos os seus hábitos, todas as suas ações. Sua loucura não estava unicamente em um princípio falso; ela tinha penetrado em tudo e tudo viciado. Andar na rua, passar diante de uma igreja, entrar em um carro, abrir cartas, escrevêlas, entrar em casas de comércio, trabalhar, ler, tudo isso lhe parecia impossível: tudo isso se fazia com a ajuda de uma vontade firme de nossa parte. O desejo das visitas do marido e o temor da obreia nos foram nisso poderosos aliados.

Contudo, a doente encontrava ainda, mesmo isso fazendo progressos em direção à cura, um meio satisfatório de contentar seu delírio. Ela passeava, agia, obedecia, mas nunca estava só. Alguém sempre a vigiava e, por conseguinte, era vista sempre. Ora, se era vista, era certo que ela não roubava, não profanava hóstias, e isso era para ela um grande motivo de segurança. Era necessário subtrair-lhe esse motivo de segurança, pois ele não estava na ordem das coisas razoáveis. Como fazer? Dispensar a doente ${ }^{2}$ Ela não o queria, e não se tinha nenhum meio de forçá-la. Deixá-la no meio do caminho? Tal decisão era muito perigosa: a doente poderia se precipitar sob uma roda ou se jogar no rio. Importava, entretanto, retirar-lhe o apoio que servia de alimento a seu delírio. M. Perrot percebeu uma coisa muito simples e bastante astuciosa: era só fechar os olhos. Quando, distraindo-se, $\mathbf{M}^{\text {me }}$ Louise desvairava seja em palavras, seja em ações, $M$. Perrot largava-lhe o braço e fechava os olhos. Esse remédio sempre agia, seu efeito nunca falhou. O que havia ainda de importante para obter foi obtido seja fechando os olhos, seja ameaçando fechá-los. Entrar em uma igreja, assistir à missa, manter-se convenientemente, não ter em seguida nem perturbação nem arrependimentos, escrever cartas, selá-las mesmo com obreia branca, isso se operou sob a influência do remédio imaginado por M. Perrot.

Tudo parecia ir bem: freqüentemente o espírito parecia completamente livre; $\mathrm{M}^{\mathrm{me}}$ Louise regressava gradativamente à vida comum. Ela via freqüentemente o marido, escrevia para a família, e não duvidava mais da possibilidade de retornar à sua casa, quando, sem motivo conhecido, e isso por duas vezes em épocas muito próximas, ela renova as tentativas de suicídio, já realizadas antes que eu a conhecesse. Um dia, dá à sua criada de quarto uma tarefa e essa tivera a inabilidade de cumpri-la. Deixada só, a doente correu rapidamente em direção a uma estrada de ferro que não ficava muito longe da casa onde se encontrava. Como tinha escolhido a hora da passagem de um comboio, teria se precipitado sob as rodas dos vagões se não a tivéssemos impedido. Um outro dia, apesar da redobrada vigilância, foi surpreendida estrangulando-se com os cordões de sua touca de dormir.

2. Envoyer la malade se promener seule equivale à nossa expressão "vai passear” e tem o sentido de deixá-la por sua conta, portanto, optei por traduzir como, “dispensá-la”. 


\section{$\begin{array}{lllllll}R & E & V & I & S & T & A\end{array}$

Estes dois acidentes, que inesperadamente interromperam a convalescença, só a atrasaram um pouco e, no final de dezembro de 1841, isto é, um pouco menos de seis meses após ter sido colocada em tratamento, $\mathrm{M}^{\text {me }}$ Louise estava perfeitamente bem.

O estado físico cessou de nos dar inquietações a partir do momento em que a doente consentiu em alimentar-se: o corpo estava depauperado, o estômago tinha sofrido; bastou uma boa alimentação para afastar todo perigo e mesmo todo acidente grave. Um único fenômeno que persistiu até o retorno da razão foi a disposição às equimoses que se produziam sob a influência da menor pressão. De resto, as gengivas estavam sãs, e não havia, além disso, aparência de uma afecção escorbútica. $\mathrm{M}^{\mathrm{me}}$ Louise regressou à sua casa, não cessou de estar inteiramente bem. Nenhuma idéia análoga àquelas que caracterizavam sua doença, ou que pareciam predispô-la, dominou seu espírito como tinha acontecido durante longos anos. Ela foi tocada no que tinha de mais caro. Algumas pessoas de sua família ficaram gravemente doentes; ela perdeu o filho mais velho e, no entanto, não experimentou, em seguida a essas desgraças, nenhuma alteração do espírito. Muito pouco tempo depois de me ter deixado, sua razão estava tão sólida que se acreditou poder fazê-la comungar. Se me tivessem consultado, eu teria dito para esperar ainda, mas passou-se por cima disso, e não houve motivo para se lamentar.

Assim, apesar de uma predisposição natural às doenças nervosas, predisposição que se tomou muito freqüentemente como um presságio de incurabilidade e de um grande abandono de sua liberdade moral, $\mathbf{M}^{\text {me }}$ Louise curou-se e há quatro anos seu espírito mantém-se em um estado tal que as pessoas que a conheceram antes, olham-na como muito mais forte do que ela jamais o foi.

Essa opinião, emitida pelas pessoas que viram $\mathrm{M}^{\mathrm{me}}$ Louise antes e após seu tratamento, merece ser destacada. Perguntar-se-á como poderia ocorrer que, após uma doença mental, o espírito se encontre fortificado e melhor do que era no estado de saúde habitual; admitir-se-á, antes, que o contrário deveria acontecer. É preciso agora distinguir: se houve delírio agudo, mania, furor, espantar-se-ia com razão que, após o tratamento quase exclusivamente físico empregado contra essas doenças, o espírito tivesse feito alguns progressos; mas após uma doença mental, puramente mental, e cujo tratamento foi um tipo de educação, não se pode, não se deve nisso ser assim, quando a cura foi completa e quando, após a cura, a higiene foi bem e muito longamente dirigida. A educação é a alimentação do espírito; boa, ela torna os espíritos sãos; negligente ou ruim, torna os espíritos doentes. Claro que ela deve ser apropriada às disposições naturais, ao caráter, sem o que não será jamais boa. E se o caráter é fraco, se as disposições naturais não são felizes, a educação dada durante o primeiro ano não basta, é preciso continuála modificando-a conforme a necessidade. Do contrário, as excentricidades, as 
bizarrias vão crescendo e exagerando-se até a loucura. Concebe-se, então, qual será o ofício da medicina: refazer a educação. Por esse meio, o espírito do doente se fortifica e torna-se capaz de lutar com vantagem contra as tendências às quais havia sucumbido.

Muitos alienados, durante a convalescença, ficaram surpresos em me ouvir imputar-lhes defeitos que não reconheciam em si e perguntavam como era possível que não lhes tivessem feito ainda notá-los. Refletindo nisso, compreendiam que ninguém tinha tomado o trabalho de lhes dar a advertência da qual teriam tido necessidade; o que, aliás, teriam achado muito ruim. Reconheciam, não sem surpresa, que em seu estado de doença, dando ao médico direitos sobre eles de um tutor ou de um pai, proporcionou-lhes a dupla vantagem de curarem-se e de se capacitarem para refutar, no futuro, as chances de uma recaída. Eu conheço e vejo no mundo várias pessoas que, depois de uma semelhante educação, são agora superiores ao eram antes da doença. 